\title{
Effect of black tea on the transverse strength of heat- polymerized acrylic resin
}

\author{
Eni Rahmi*, Zulkarnain Agus**, Riezka Hanafiah Putri** \\ *Department of Prosthodontics Faculty of Dentistry Universitas Andalas, Indonesia \\ **Department of Biomedics Faculty of Medicine Universitas Andalas, Indonesia
}

\begin{abstract}
Introduction: Heat-polymerized acrylic resin is the most basic denture material used. One of the mechanical properties of an acrylic resin is its transverse strength. The transverse strength test provides an overview of the material's durability in accepting the load at mastication. Consumption of tea, especially black tea in the world placed the second most consumed. The purpose of this study was to determine the effect of black tea on the transverse strength of heat-polymerized acrylic resin. Methods: This research was an experimental laboratory with 24 samples of heat-polymerized acrylic resin plate with the size of $65 \times 10 \times 2.5 \mathrm{~mm}$. The sample was divided into 6 groups, each consisted of 4 samples. The first, second, and the third groups were immersed in aquadest for consecutively 1, 4, and 20 days. The fourth, fifth, and sixth groups were immersed in the black tea for consecutively 1, 4, and 20 days. The transverse strength was tested using the three-point bending method with the Universal Testing Machine. The results of the transverse strength measurement were then analyzed statistically by the One-way ANOVA test and Holm's sequential Bonferroni posthoc test as an advanced test. Results: The results of the statistical test showed that $p<0.05(p=0.000)$ which means that the six groups have a significant difference in the average value of the transverse strength. Conclusion: The conclusion of this research was the black tea immersion duration was affecting the transverse strength differences of the heatpolymerized acrylic resin.
\end{abstract}

Keywords: Heat-polymerized acrylic resin, black tea, transverse strength

P-ISSN 1979-0201, e-ISSN 2549-6212 Available from: http://jurnal.unpad.ac.id/pjd/article/view/14469

DOI: 10.24198/pjd.vol29no3.14469

Submission: Jul 2017 Publishing: Nov 2017

\section{INTRODUCTION}

Acrylic resin is the most popular denture base material in the field of dentistry. ${ }^{1}$ The most widely used type of resin is heat-polymerized acrylic resin because it has several advantages, including aesthetic qualities, good colour stability, nonirritating, non-toxic, low relative price, low residual monomer, small porosity, and easy processing, manufacture and repair. ${ }^{2,3}$ 
One of the mechanical properties of an acrylic resin is a transverse strength. ${ }^{1}$ Transverse strength represents the different types of forces received in the mouth of artificial teeth during mastication. The transverse power test is a composite of tensile measurements, compressive forces, and shear forces simultaneously. This test provides an overview of the material's durability in accepting the load at mastication..$^{1,4,5}$

The transverse strength of the acrylic resin is influenced by various factors such as molecular weight of polymer, residual monomer, plasticizer composition, material thickness, load and moisture content. ${ }^{6}$ In addition, Shen' ${ }^{7}$ research showed that phenols can affect the transverse strength of hot acrylic resin polymerization because it will form microporosity and cause chemical destruction on the surface of the acrylic resin plate. One of the beverages containing phenol compounds is black tea. The main chemical compounds in black tea include theaflavin, thearubigins, flavonol, caffeine, phenolic acids, and amino acids. Theaflavin and thearubigins are polyphenol-class pigment compounds produced during fermentation and play a role in the typical colour of black tea. ${ }^{8,9}$

Tea consumption in the world, especially black tea ranks second after water consumption. A study conducted by the UK National Diet and Nutrition Survey (NDNS) with a sample of 7000 adults showed $77 \%$ of them drank tea with an average consumption of 2.3 cups ( $540 \mathrm{ml}$ ) of tea per day. ${ }^{8}$ The purpose of this study was to determine the effect of black tea on the transverse strength of heat-polymerized acrylic resin.

\section{METHODS}

This research was a laboratory experimental with a sample of heat cure acrylic plate QC 20 measuring $65 \times 10 \times 2.5 \mathrm{~mm}$ as many as 24 pieces. The sample was divided into 6 groups, each consisting of 4 samples. Prior to testing, the acrylic resin plate was immersed in a sterile aquadest at $37^{\circ} \mathrm{C}$ for 48 hours in order to reduce the residual monomer present in the acrylic resin. The first, second, and third groups were the immersed in aquadest for 1 , 4 , and 20 days. The fourth, fifth, and sixth groups were immersed in black tea for 1,4 , and 20 days. The black tea drink was made according to the manufacturer's recommendation: 1 bag of tea bags weighing 2 grams dipped in $200 \mathrm{ml}$ water with temperature $100^{\circ} \mathrm{C}$ for 2 minutes on a measuring cup. After that, the tea bag was lifted and the black tea drink was allowed to cool to $37^{\circ} \mathrm{C}$.

The solution was changed every 24 hours and between alternating solutions, rinsing with aquadest. Testing of transversal strength used three-point bending method. The maximum load measurements that could be received by the specimen were done by Universal Testing Machine then calculated the transverse power in accordance with the formula of flexural strength measurement. Differences in transverse strength values between groups were statistically analyzed by One-way ANOVA test and Holm's sequential Bonferroni posthoc test.

\section{RESULTS}

The results showed that there was a difference in the average value of the transverse strengths between groups. The average value of transverse strength decreases based on the duration of immersion. The largest mean transversal strength was found in samples immersed in aquadest for 1 day at $187.09 \pm 7.38 \mathrm{MPa}$, while the smallest transverse mean strength was found in samples immersed in black tea for 20 days at $160.17 \pm 6.03$ Mpa, as seen in Table 1.

The One-way ANOVA test was then performed to determine whether there were any differences in the transverse strengths of the six groups. The results showed that the $p$-value $<0.05$ $(p=0.000)$ which means that the six groups have significantly different mean values of transversal strength. A further test was the Holm's sequential Bonferroni posthoc test (Tab. 2) was performed to find out which groups were different. The value of transverse strength of acrylic resin of heat polymerization soaked in aquadest and black tea with the same immersion time has no significant difference $(p 1$ day=1.000; $p 4$ days $=1.000 ; p$ 20 days $=0.648$ ). Meanwhile, groups immersed in aquadest for 1 and 4 days had a significant difference to the group immersed in aquadest and black tea for 20 days. Groups immersed in black tea for 1 and 4 days also had a significant difference to the group immersed in black tea for 20 days. 
Table 1. The transverse strength average value of the heat-polymerized acrylic resin (MPa)

\begin{tabular}{rccc}
\hline Solution & Immersion duration & N & Average value \pm SD \\
\hline \multirow{3}{*}{ Aquadest } & 1 day & 4 & $187.09 \pm 7.38$ \\
& 4 days & 4 & $186.60 \pm 5.56$ \\
& 20 days & 4 & $169.80 \pm 8.50$ \\
Black tea & 1 day & 4 & $183.23 \pm 3.42$ \\
& 4 days & 4 & $181.84 \pm 5.44$ \\
& 20 days & 4 & $160.17 \pm 6.03$ \\
\hline
\end{tabular}

Table 2. The Holm's sequential Bonferroni posthoc test result

\begin{tabular}{lcccccc}
\hline Treatment group & $\begin{array}{c}\text { Aquadest for } \\
\text { 1 day }\end{array}$ & $\begin{array}{c}\text { Aquadest for } \\
\text { 4 days }\end{array}$ & $\begin{array}{c}\text { Aquadest for } \\
\text { 20 days }\end{array}$ & $\begin{array}{c}\text { Black tea for } \\
\text { 1 day }\end{array}$ & $\begin{array}{c}\text { Black tea for } \\
\text { 4 days }\end{array}$ & $\begin{array}{c}\text { Black tea for } \\
\text { 20 days }\end{array}$ \\
\hline Aquadest for 1 day & - & 1.000 & $0.016^{*}$ & 1.000 & 1.000 & $0.000^{*}$ \\
Aquadest for 4 days & 1.000 & - & $0.020^{*}$ & 1.000 & 1.000 & $0.000^{*}$ \\
Aquadest for 20 days & $0.016^{*}$ & $0.020^{*}$ & - & 0.107 & 0.212 & 0.648 \\
Black tea for 1 days & 1.000 & 1.000 & 0.107 & - & 1.000 & $0.001^{*}$ \\
Black tea for 4 days & 1.000 & 1.000 & 0.212 & 1.000 & - & $0.002^{*}$ \\
Black tea for 20 days & 0.000 & 0.000 & 0.648 & $0.001^{*}$ & $0.002^{*}$ & - \\
\hline
\end{tabular}

\section{DISCUSSION}

This study was conducted to determine the effect of black tea drink on the transverse power of heat acrylic polymerization resin. In this study, immersed heat acrylic resin plate in aquadest as a control group and black tea drink as treatment group respectively for 1,4 , and 20 days. The results of the statistical analysis indicated that heat acrylic resin polymerization resin immersed in aquadest for 1 and 4 days had significant differences in transversal strength value against acrylic resin heat polymerization soaked in aquadest for 20 days. This significant difference in the value of transverse strength is thought to be due to the length of immersion of the acrylic resin. The longer the duration of the immersion, the more water was absorbed. ${ }^{10}$ The water absorption into the resin matrix will decrease the transverse strength since increased moisture content will lead to an increase in the distance between the molecular chains and will act as plasticizers. ${ }^{11}$

Acrylic resins like other polymers have two kinds of bonds, namely primary bonds and secondary bonds. The primary bond is the bond between the atoms in the chain while the secondary bond is the bond between the chains. The acrylic resin primer bond has good strength, but the secondary bond is weak. The secondary bond of weak acrylic resin causes the water molecule to penetrate into the matrix. The water ion in the matrix will bind to the hydroxyl group and break the polymer chain. The breakdown of the polymer chains on the resin matrix will cause the intercellular space to permit the absorption of water. ${ }^{12}$ Water absorption will persist through the diffusion mechanism. As a result, the water molecule was penetrating, occupy a position between the chain and force the polymer chain to separate. The presence of water molecules in the polymerized mass causes the resin matrix to expand and act as a plasticizer thus affecting its strength. Anusavice ${ }^{1}$ stated that acrylic resin takes about 17 days to reach saturation, so for 17 days the acrylic will continue to absorb water until it reaches its saturation point. Acrylic resins soaked in black tea drink have a smaller transverse power value than the soaked acrylic resin in aquadest either at immersion for 1,4 , or 20 days. This is because, in addition to water absorption, phenol compounds contained in black tea also affect its transverse power. Phenol is a substance that can degrade chemical bonds of acrylic resins. According to Combe $^{2}$, acrylic resins are polymers of long polyester forms consisting of methyl methacrylate units repeated with low polarity, while phenols are acidic with high polarity. Esters in the acidic atmosphere will be 
hydrolyzed to form carboxylic acids and alcohols. The split polyester causes degradation of the chemical bonds of the acrylic resin resulting in a decrease in its transverse strength. ${ }^{2}$ Nevertheless, the transverse value of acrylic resin immersed in black tea and aquadest with the same immersion period has no significant difference. This can happen because the concentration of black tea used in this study was very small that is $1 \%$ as the concentration of black tea drink consumed daily. The smaller the concentration of black tea the smaller the phenol contained in it. According to Shen ${ }^{7}$, the pure phenol concentration that can damage the chemical bond of acrylic resin is $5 \%$ so that the acrylic resin soaked in a solution containing phenol compounds less than $5 \%$ will not have significant chemical bond degradation. ${ }^{7}$ In addition, Sakaguchi and Powers ${ }^{11}$ stated that the resin acrylic has good resistance to weak acids. ${ }^{11}$ The content of ethylene glycol dimethacrylate (EGDMA) as a cross-linking agent in acrylic resin QC 20 also plays a role in improving the physical and mechanical properties of resin. ${ }^{11,16}$

\section{CONCLUSION}

The conclusion of this research was the black tea immersion duration was affecting the transverse strength difference of the heat-polymerized acrylic resin.

\section{REFERENCES}

1. Anusavice KJ. Phillip's science of dental material. $12^{\text {st }}$ ed. St. Louis: Saunders-Elsevier; 2003. p. 74-98, 722-47.

2. Combe EC. Notes on dental materials (Dental series). $6^{\text {th }}$ ed. London: Churchill Livingston; 1992. p. 255-67.

3. Hussain S. Textbook of dental materials. New Delhi: Jaypee Brothers Medical Pub.; 2008. p.
104-50

4. Jagger DC, Jagger RG, Allen SM, Harrison A. An investigation into the transverse and impact strength of "high strength" denture base acrylic resins. J Oral Rehabil Mar 2002;29(3):263-7.

5. Hasan RH. Comparison of some physical properties of acrylic denture base material cured by water bath and microwave techniques. Al-Rafidain Dent J 2003;3(2):14314.

6. Pisani MX, da Silva CHL, Paranhos HFO, Souza RF, Macedo AP. The effect of experimental denture cleanser solution ricinus communis on acrylic resin properties. Mat Res Jul-Sep 2010;13(3):369-73. DOI: 10.1590/S151614392010000300015

7. Shen C, Javid NS, Colaizzi FA. The effect of glutaraldehyde base desinfectant on denture base. J Prosthet Dent May 1989;61(5):583-9

8. Gardner EJ, Ruxton CH, Leeds AR. Black teahelpful or harmful? Areview of the evidence. Eur J Clin Nutr Jan 2007;61(1):3-18. DOI: 10.1038/sj.ejcn.1602489

9. Mazza G, Oomah BD. Herbs, botanicals and tea. 1st ed. Boca Raton: CRC Press; 2000. p. 265-80.

10. Al-Nori AK, Hussain AMA, Rejab LT. Water sorption of heat cured acrylic resin. AlRafidain Dent J. 2007;7(2):186-94.

11. Sakaguchi RL, Powers JM. Craig's restorative dental materials. $13^{\text {th }}$ ed. Philadelphia: MosbyElsevier; 2012: p. 52-78, 514-49.

12. O'Brien WJ. Dental material and their selection. $3^{\text {rd }}$ ed. Chicago: Quintessence Publishing Co. Inc.; 2002. p. 74-89.

13. Faot F, Panza LHV, Garcia RCMR, Del Bel Cury AA. Impact and flexural strength and fracture morphology of acrylic resins with impact modifiers. Open Dent J 2009;3:137-43. DOI: $10.2174 / 1874210600903010137$ 